\title{
Anatomical Snuffbox and it Clinical Significance. A Literature Review
}

\author{
La Tabaquera Anatómica y su Importancia Clínica. Una Revisión de la Literatura
}

\author{
Aladino Cerda ${ }^{* * *} \&$ Mariano del Sol ${ }^{* * *, * * * *}$
}

CERDA, A \& DEL SOL, M. Anatomical snuffbox and it clinical significance. A literature review. Int. J. Morphol., 33(4):1355-1360, 2015.

SUMMARY: The anatomical snuffbox is a small triangular area situated in the radial part of the wrist, often used to perform clinical and surgical procedures. Despite the frequency with which this area is used, there is scarce information in literature about its details. The objective of this study is detailed knowledge of the anatomical snuffbox's anatomy and its components, the reported alterations at this portion, besides the clinical uses and significance of this area. Scaphoid.

KEY WORDS: Hand; Wrist; Anatomical Snuffbox; Radial artery; Cephalic vein; Superficial branch of radial nerve;

\section{INTRODUCTION}

The anatomical snuffbox (AS) is a depression in wrist's radial part, limited by the tendons of abductor longus muscle, extensor pollicis brevis and extensor pollicis longus muscles (Latarjet \& Ruíz-Liard, 2007). This little triangular area is often used to perform clinical procedures as the cannulation of the cephalic vein, and surgical procedures as placing arteriovenous fistula between the radial artery and cephalic vein, among other uses.

According to Tubbs et al. (2006) there is scarce detailed information about AS in literature.

To do this review, we consulted articles in English and Spanish, published in PubMed and ScienceDirect databases. The research was realized using terms like "anatomical snuff box" and "fovea radialis". Anatomy texts were also used.

\section{ANATOMY}

AS is a depression located in radial part of the wrist (Fig. 1), is laterally limited by the tendons of abductor pollicis longus and extensor pollicis brevis muscles, and medially limited by the tendon of extensor pollicis longus muscle
(Latarjet \& Ruíz-Liard). This triangular structure presents a base formed by the distal margin of the retinaculum of extensor muscles (Kahle et al., 1995), and a vertex conformed by the attachment of the tendons of extensor pollicis longus and extensor pollicis brevis muscles (Fig. 2) (Latarjet \& Ruíz-Liard). The roof is formed by the skin and superficial

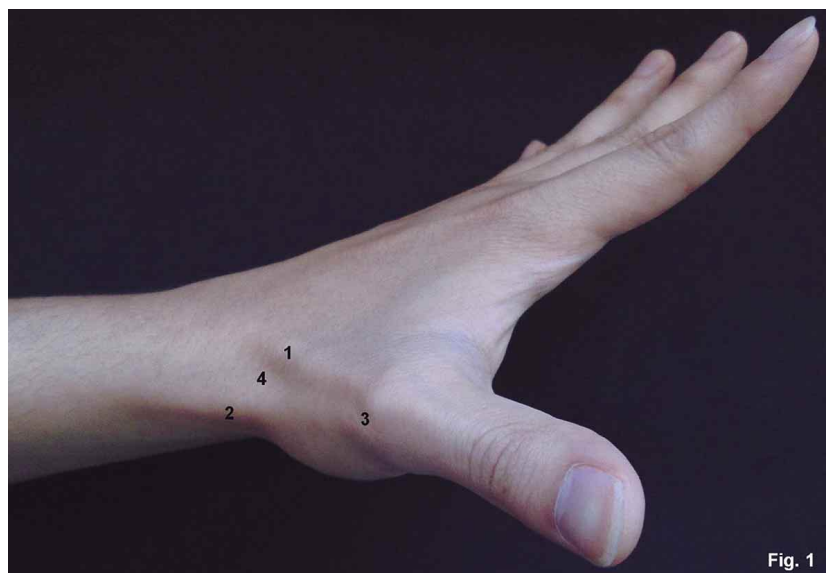

Fig. 1. Posterior view of radial part of the left wrist. $1=$ tendon of extensor pollicis longus muscle; $2=$ tendon of extensor pollicis brevis muscle; $3=$ head of the first metacarpal bone; $4=$ anatomical snuffbox.

\footnotetext{
* Unidad de Morfología, Departamento de Ciencias Básicas Biomédicas, Facultad de Ciencias de la Salud, Universidad de Talca, Talca, Chile. ** Programa de Magíster en Ciencias, mención Morfología, Facultad de Ciencias de la Salud, Universidad de la Frontera, Temuco, Chile.

*** Facultad de Medicina, Centro de Excelencia en Estudios Morfológicos y Quirúrgicos (CEMyQ), Universidad de la Frontera, Temuco, Chile.

**** Center for Biomedical Research, Universidad Autónoma de Chile, Temuco, Chile.
} 


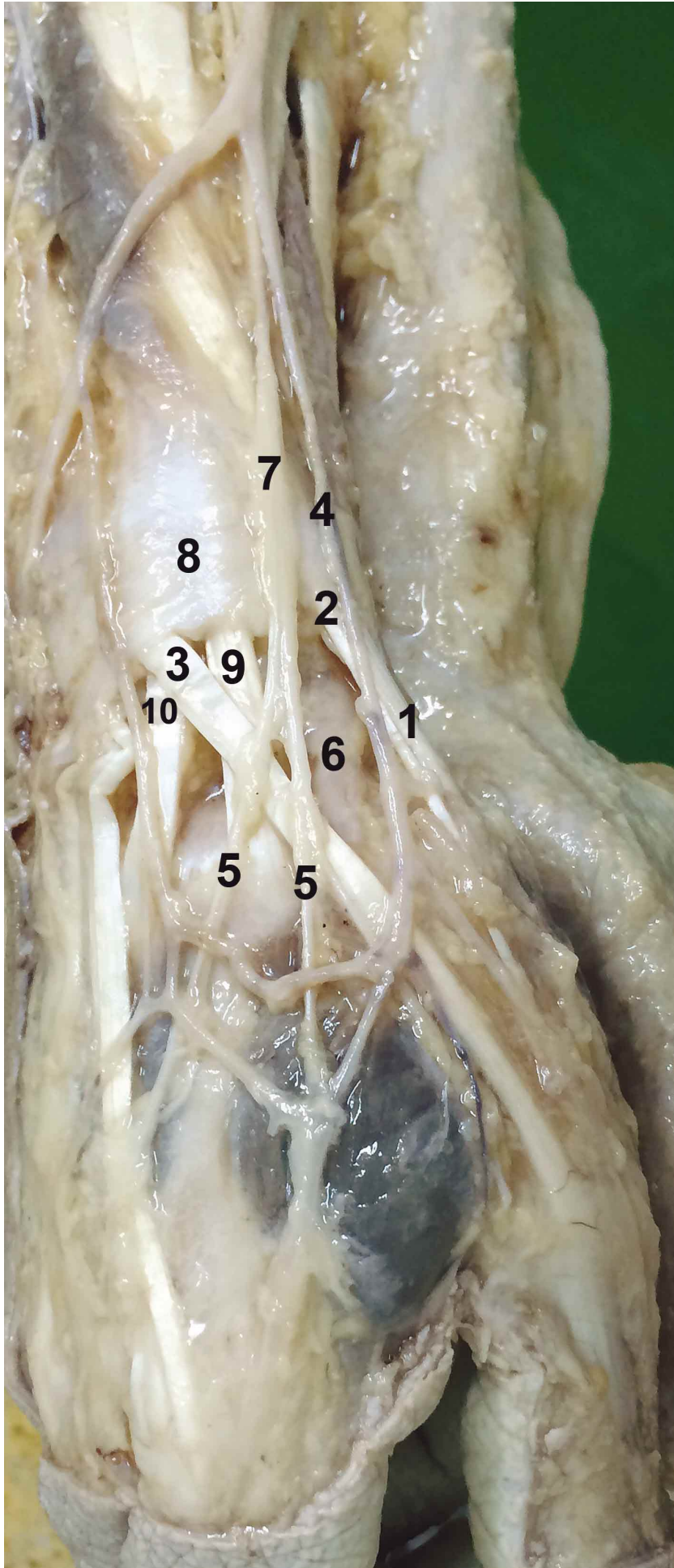

Fig. 2. Posterior view of radial part of the right wrist. $1=$ tendon of abductor pollicis longus muscle; $2=$ tendon of extensor pollicis brevis muscle; $3=$ tendon of extensor pollicis longus muscle; $4=$ cephalic vein; $5=$ terminal branches of the superficial branch of radial nerve; $6=$ radial artery; $7=$ superficial branch of radial nerve; $8=$ retinaculum of extensor muscles; $9=$ tendon of extensor carpi radialis longus muscle; $10=$ tendon of extensor carpi radialis brevis muscle.

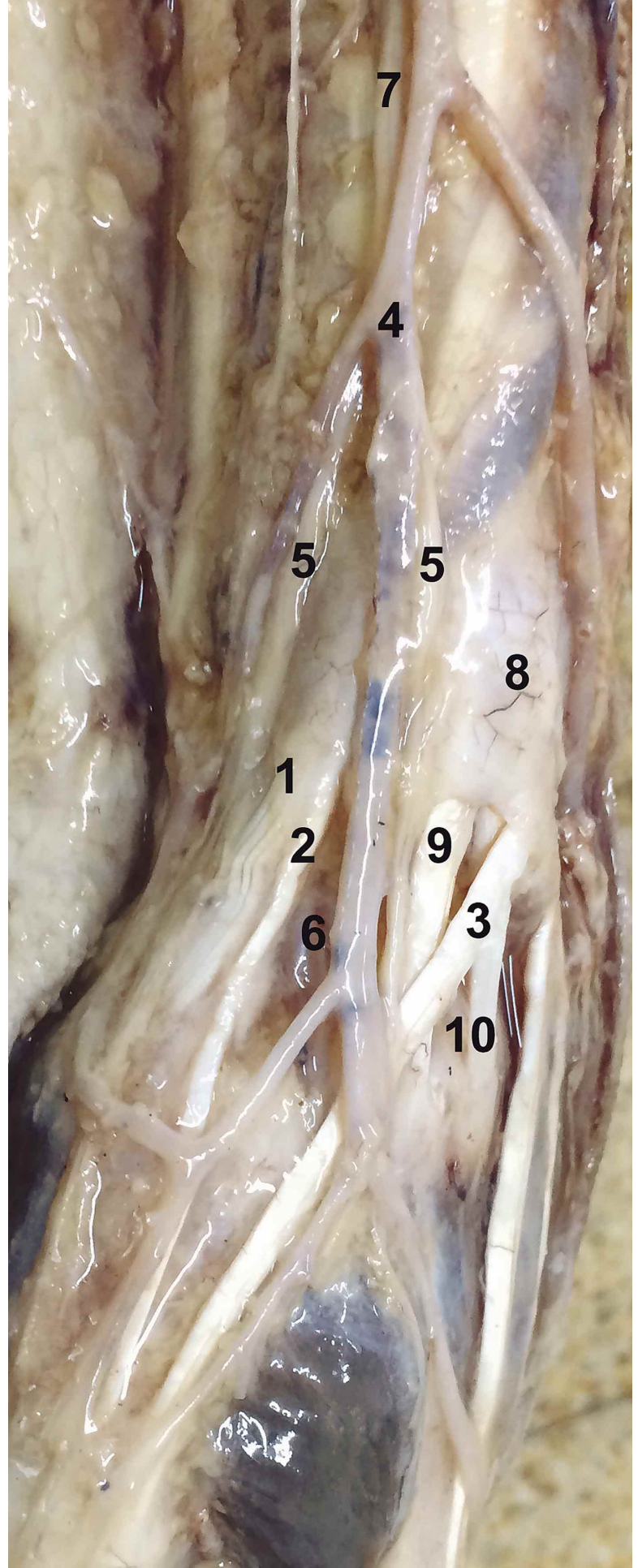

Fig. 3. Posterior view of radial part of the left wrist. $1=$ tendon of abductor pollicis longus muscle; $2=$ tendon of extensor pollicis brevis muscle; $3=$ tendon of extensor pollicis longus muscle; $4=$ cephalic vein; $5=$ terminal branches of the superficial branch of radial nerve; $6=$ radial artery; $7=$ superficial branch of radial nerve; $8=$ retinaculum of extensor muscles; $9=$ tendon of extensor carpi radialis longus muscle; $10=$ tendon of extensor carpi radialis brevis muscle. 
fascia, in where we can fine the cephalic vein (CV) and superficial branch of the radial nerve (SBRN) (Tubbs et al.), and the ground is conformed by the distal radius, scaphoid, trapezium and the base of the first metacarpal bone (Grechenig et al., 1999).

There are the tendons of the extensor carpi radialis muscles and the radial artery (RA) at the AS bottom (Fig. 3) (Kahle et al.; Rouviere \& Delmas, 2005; Latarjet \& RuízLiard). The mentioned artery origins the dorsal carpal branch at this level (Kahle et al.) and the princeps pollicis artery (Latarjet \& Ruíz-Liard).

According to Testut \& Latarjet (1975), in a live person, when the muscles that circumscribe this area contract, the skin becomes depressed forming a prolonged shallow fossa, in which the ancient deposited their snuff before drawing it directly through the nostrils; therefore its name.

Regarding its size, in the study of Tubbs et al., the average height of the AS was $6 \mathrm{~cm}$ and the average width at its base was $1.5 \mathrm{~cm}$.

In terms of content, the SBRN is one of its terminal branches of the radial nerve (Rouviere \& Delmas). Both Rouviere \& Delmas as Latarjet \& Ruíz-Liard, indicate that this branch has 3 terminals; one lateral branch, one intermediate and one medial. The study by Tubbs et al., showed that the SBRN in general was deep to the VC and had two branches that crossed the AS in 29 of the 30 samples, and 3 branches in 1 of 30 samples. These branches originated always distally to the tendon of extensor pollicis brevis muscle. Samarakoon et al. (2011) dissected 25 wrists and forearms, and observed that in most of the samples (68\%), the CV and the SBRN crossed each other at least once, and even twice. In a study by Robson et al. (2008), the cephalic vein was closely related $(<2 \mathrm{~mm})$ with the SBRN in $80 \%$ of cases (20 of 25 dissections).

According Mehigan \& McAlexander, (1982) the CV and RA almost invariably coursed through the AS and was found less than $5 \mathrm{~mm}$ one from another. In the study by Robson et al., in two of the 25 upper limbs, both the lateral cutaneous nerve of forearm (LCNF) and SBRN were very close $(<2 \mathrm{~mm}$ ) to the $\mathrm{CV}$ (the LCNF at the ulnar side and SBRN deep to the CV). In the other samples, only the SBRN was closely related to the CV. Tubbs et al., Observed that $70 \%$ of the samples were connections between the vena comitante of the RA and the CV within the limits of the AS. Also they noted that the $\mathrm{CV}$ was found more frequently in the medial part of the AS.

Rouvière \& Delmas describe that AR in the AS penetrates going deep to the tendons of the abductor pollicis longus and extensor pollicis brevis muscles. Also they noted that the mentioned artery is in the bottom of this structure, onto Trapezium bone. However Tubbs et al., showed that in most cases the RA is located very near the base of the AS and not located distally within this region. Robson et al., found that the RA was closely related $(<2 \mathrm{~mm})$ with the SBRN, near the styloid process of radius in $48 \%$ of samples, while $24 \%$ were close to LCNF, rather than SBRN. In all cases, these nerve branches were either superimposed on the artery or located on radial side of it. Kahle et al. and Rouviere \& Delmas indicate that at the level of AS, AR originates the dorsal carpal branch, Latarjet \& Ruíz-Liard, add that also originates the princeps pollicis artery at this level. In the study by Tubbs et al., both arteries originated at AS level in all samples. In one sample, two dorsal carpal branches were observed, and in another, a small branch of the princeps pollicis artery travelled superficially along the $\mathrm{CV}$. In addition, five samples showed a muscular branch originating from the princeps pollicis artery or directly from the RA for the adductor pollicis brevis muscle.

Berger et al. (2003) states that the dorso-ulnar corner of the AS contains only the tendon of extensor carpi radialis longus muscle, but according to Tubbs et al., the tendon of extensor carpi radialis brevis can also be found in the AS, depending on how distal the retinaculum of extensor muscles is, and how medial the dorsal tubercle of the radius is found.

Corfitsen et al. (1989) describe, in a radiological study, a pad of fat within the AS. Tubbs et al., observed this shapely fat collection between the styloid process and the base of the first metacarpal in all samples. This pad completely covered the RA in its passage by the AS in most samples.

\section{ALTERATIONS AT ANATOMICAL SNUFFBOX LEVEL REPORTS}

Yoshii et al. (2000) described the cases of two patients with compression of the SBRN, due to a ganglion cyst. Amar et al., (2012) reported the case of a 40 years old patient with a compressive lipoma affecting the lateral terminal branch of the SBRN at this level.

Naeem et al. (2012) reported that after a failed attempt to canalize the CV in the AS, a woman suffered a strong electric pain irradiated from the back of the hand to the posterior region of the upper portion of right arm, with a loss of sensitivity in the first interdigital space and radial side of the thumb. Nine months after, she was diagnosed with a neuroma of the SBRN. 
There are several reports in the literature of lesions of the RA at the AS, including; aneurysms (Miura et al., 2004; Luzzani et al., 2006;), an aneurysm initially misdiagnosed as a ganglion cyst (Walton \& Choudhary, 2002), idiopathic aneurysm (Santos et al., 2008), bilateral aneurysm in a patient with Marfan syndrome (Yukios et al., 2009), mycotic aneurysm of the dorsal carpal branch (Poirier \& Stansel, 1972) and traumatic aneurysms (Wenger et al., 1980).

McNamara et al. (1998) noted that between 1984 and 1995 , nine patients were treated with spontaneous thrombosis of the radial artery in the region of the AS, all of whom had ischemic symptoms in the index finger and / or the thumb.

\section{ANATOMICAL SNUFFBOX USES AND CLINICAL SIGNIFICANCE}

According to Naeem et al., the dorsal radial portion of the wrist is a popular site for venous cannulation, as the $\mathrm{CV}$ can be easily identified there. Samarakoon et al., indicate that superficial position of the SBRN is vulnerable to injury during this procedure.

Kretschmer et al. (2001) indicate that the SBRN is the third most injured peripheral nerve, after accessory and common fibular nerves. This injury may be the result of fractures, lacerations, sustained pressure or may be iatrogenic (Robson et al.). Both Robson et al. and Samarakoon et al., indicate that to avoid iatrogenic injury of the SBRN, need to avoid cannulation of the CV in the distal third of the forearm. Vialle et al. (2001) concluded that to avoid injury to this nerve, $\mathrm{CV}$ puncture must be at least $12 \mathrm{~cm}$ above the styloid process of the radius.

Recent advances in ultrasound technology have allowed both morphological analysis and functional assessment of various diseases, based on the control of blood flow by Doppler ultrasound (Ban et al., 2005). The wave forms obtained by this method are influenced by the angle between the ultrasound beam and the direction of blood flow. Said angle of incidence is critical in the analysis, and should be less than $60^{\circ}$ to reduce the error to less than $20 \%$. If the angle of incidence is close to $0^{\circ}$, the signals will be more accurate. At AS level, average incidence angle is $11.5 \pm 10.8^{\circ}$, so that this region is ideal for Doppler blood flow analysis (Ban $e t$ al.).

Kochi et al. (2003) argue that monitoring blood flow by color Doppler method in the AS is useful to examine the permeability of radial and ulnar arteries, thus evaluating the circulation of the hand, before harvesting the RA for coronary artery bypass grafting, and can be clinically applied as a reliable alternative to Allen test.
In 1982, Bonalumi et al., noted that the surgically created arteriovenous fistula (AVF) had become the method of choice for achieving vascular access for hemodialysis maintenance. They conducted between 1972 and 1980, 177 AVF from end to end in the AS between the CV and the RA of the non dominant upper limb in patients undergoing hemodialysis. The survival rate was $83.1 \%$ at 12 months and $46.3 \%$ at 6.5 years, levelling up to 9 years. The average survival rate was 6 years. In his article he indicates that $50 \%$ of final failures were due to aneurysm formation by repeated venous puncture at the same site and subsequent obliteration of the upper venous segment. From the 154 AVF made during five years at the AS level between the CV and RA, by Mehigan \& McAlexander, $132(86 \%)$ produced a satisfactory blood access that worked for 6-60 months. In 15 patients (9.7\%), there was venous congestion of fingers; which was solved ligand the CV distally to the fistula. Bonalumi et al., explained that factors that seem to lead to AVF failure are the preference of dialysis personnel to inserting needles into the dilated areas, and patient's desire to always want the same vein puncture site due to insensitivity of skin in that area. According to Giacchino et al. (1979), the correct procedure for a fistula should be to changed the venipuncture site at each dialysis moment, thus allowing a regular distention of whole venous tract.

Mehigan \& McAlexander indicate that the first site chosen for hemodialysis should be as distal as possible in the limb, while preserving the more proximal areas for future access. Almost constant anatomical juxtaposition of RA and $\mathrm{CV}$ in the AS make fistula procedure exceptionally simple, requiring minimal dissection and the preservation of the more proximal sites for later fistula, in case of being necessary. According Bonalumi et al., the AS can be regarded as the most distal site available for vascular access for hemodialysis. Mehigan \& McAlexander added that due to the minimal dissection performed with this technique, wound complications and morbidity are very low.

Stanziale et al. (2008), concluded that the AVF is the best vascular access for chronic hemodialysis in patients with end-stage renal disease.

Tao et al. (2010), compared AVF in the AS and AVF in the forearm in 214 hemodialysis patients with chronic renal failure, to see what was the best method for permanent vascular access before kidney transplantation. They found that the permeability rate was significantly higher in the group of the AS at 2-3 years $(p<0.05)$, and rates of incidence of pseudoaneurysm and congestive heart failure were significantly lower in the AS ( $\mathrm{p}<0.05$ ), which concluded that the AVF in the AS should be the first choice in the permanent vascular access. 
Regarding aneurysm of RA, Poirier \& Stansel, indicate that the most frequent sites of aneurysms in the hand are the thenar and hypothenar eminence, as they are the two most prominent regions which are most often used for protection. Santos et al., added that one of the factors that predispose to the formation of RA aneurysms are multiple puncture attempts.

Ellis \& Mahadevan (2010) indicate that increased tenderness on palpation in the AS is characteristic of the fracture of the scaphoid bone. Mallee et al. (2014) add that this is the most sensitive clinical test, however, if only this test is used, up to $13 \%$ of scaphoid fractures could be undiagnosed. Tubbs et al., indicate that we must also consider the fracture of distal radius, base of the first metacarpal and the trapezium bone, as they all are part of the floor of the AS. They also note that the radiological displacement of the fat pad located on the AS may suggest a fracture of one of the osseous components forming the floor of the AS, similar to the displacement of fat seen on fractures of ulna olecranon.
Doyle \& Botte (2003) concluded that as the tendons of the extensor carpi radialis muscles and extensor muscles of the thumb are in the AS, intersection syndrome, where symptomatic friction between these tendons is created, can occur in the AS.

\section{CONCLUSIONS}

Due to the multiple procedures that are performed at this level, the precise knowledge of the area and its components are crucial to avoid risks and possible consequences, such as injury to the superficial branch of the radial nerve, arteriovenous fistulas failures and radial artery aneurysms due to multiple attempts of puncture.

This review provides detailed information about the anatomical snuffbox and its clinical relevance, which can be used by health professionals maneuvering at this level, and anatomists to enhance the detail of his dissections.

CERDA, A \& DEL SOL, M. La tabaquera anatómica y su importancia clínica. Una revisión de la literatura. Int. J. Morphol., 33(4):13551360, 2015.

RESUMEN: La tabaquera anatómica, es una pequeña área triangular ubicada en la parte radial de la muñeca utilizada a menudo para realizar procedimientos clínicos y quirúrgicos. A pesar de la frecuencia con la que se utiliza esta zona, escasea la información acerca de sus detalles en la literatura. El objetivo de este estudio es conocer con detalle la anatomía de la tabaquera anatómica y sus componentes, las alteraciones reportadas a ese nivel, y los usos e importancia clínica de esta región.

PALABRAS CLAVE: Mano; Muñeca; Tabaquera anatómica; Arteria radial; Vena cefálica; Ramo superficial del nervio radial; Escafoides.

\section{REFERENCES}

Amar, M. F.; Benjelloun, H.; Ammoumri, O.; Marzouki, A.; Mernissi, F. Z. \& Boutayeb, F. Lipome compressif de la tabatière anatomique. À propos d'un cas. Ann. Chir. Plast. Esthet., 57(4):409-11, 2012.

Ban, K.; Kochi, K.; Imai, K.; Okada, K.; Orihashi, K. \& Sueda, T. Novel Doppler technique to assess systemic vascular resistance: the snuffbox technique. Circ. J., 69(6):688-94, 2005.

Berger, R. A.; Doyle, J. R. \& Botte, M. J. Wrist. In: Doyle, J. R. \& Botte, M. J. (Eds.). Surgical anatomy of the hand and upper extremity. Philadelphia, Lippincott Williams \& Wilkins, 2003.

Bonalumi, U.; Civalleri, D.; Rovida, S.; Adami, G. F.; Gianetta, E. $\&$ Griffanti-Bartoli, F. Nine years' experience with end-to-end arteriovenous fistula at the 'anatomical snuffbox' for maintenance haemodialysis. Br. J. Surg., 69(8):486-8, 1982.
Corfitsen, M.; Christensen, S. E. \& Cetti, R. The anatomical fat pad and the radiological "scaphoid fat stripe". J. Hand Surg. Br., 14(3):326-8, 1989.

Doyle, J. R. \& Botte, M. J. Surgical anatomy of the hand and upper extremity. Philadelphia, Lippincott Williams \& Wilkins, 2003.

Ellis, H. \& Mahadevan V. Clinical anatomy: applied anatomy for students and junior doctors. 10th ed. London, Wiley-Blackwell, 2010.

Giacchino, J. L.; Geis, W. P.; Buckingham, J. M.; Vertuno, L. L. \& Bansal, V. K. Vascular access: long-term results, new techniques. Arch. Surg., 114(4):403-9, 1979.

Grechenig, W.; Peicha, G.; Fellinger, M.; Seibert, F. J. \& Weiglein, A. H. Anatomical and safety considerations in establishing portals used for wrist arthroscopy. Clin. Anat., 12(3):179-85, 1999. 
Kahle, W.; Leonhardt, H. \& Platzer, W. Atlas de anatomía para estudiantes y médicos: Aparato locomotor. 3rd ed. Barcelona, Omega, 1995.

Kochi, K.; Orihashi, K. \& Sueda, T. The snuffbox technique: a reliable color Doppler method to assess hand circulation. J. Thorac. Cardiovasc. Surg., 125(4):821-5, 2003.

Kretschmer, T.; Antoniadis, G.; Braun, V.; Rath, S. A. \& Richter, H. P. Evaluation of iatrogenic lesions in 722 surgically treated cases of peripheral nerve trauma. J. Neurosurg., 94(6):905-12, 2001.

Latarjet, M. \& Ruíz-Liard, A. Anatomía humana. 4th ed. Buenos Aires, Editorial Médica Panamericana, 2007.

Luzzani, L.; Bellosta, R.; Carugati, C.; Talarico, M. \& Sarcina, A. Aneurysm of the radial artery in the anatomical snuff box. E. J. V. E. S. Extra, 11(5):94-6, 2006.

Mallee, W. H.; Henny, E. P.; van Dijk, C. N.; Kamminga, S. P.; van Enst, W. A. \& Kloen, P. Clinical diagnostic evaluation for scaphoid fractures: a systematic review and meta-analysis. $J$. Hand Surg. Am., 39(9):1683-91.e2, 2014.

McNamara, M. G.; Butler, T. E.; Sanders, W. E. \& Pederson, W. C. Ischaemia of the index finger and thumb secondary to thrombosis of the radial artery in the anatomical snuffbox. J. Hand Surg. Br., 23(1):28-32, 1998.

Mehigan, J. T. \& McAlexander, R. A. Snuffbox arteriovenous fistula for hemodialysis. Am. J. Surg., 143(2):252-3, 1982.

Miura, S.; Kigawa, I.; Miyairi, T. \& Fukuda, S. A surgically treated case of true radial arterial aneurysm in the anatomical snuffbox. Jpn. J. Vasc. Surg., 13:687-90, 2004.

Naeem, R.; Soueid, A. \& Lahiri, A. The dangers of intravenous cannulation within the anatomical snuffbox. J. Hand Surg. Eur. Vol., 37(4):362-3, 2012.

Poirier, R. A. \& Stansel, H. C. Jr. Arterial aneurysms of the hand. Am. J. Surg., 124(1):72-4, 1972.

Robson, A. J.; See, M. S. \& Ellis, H. Applied anatomy of the superficial branch of the radial nerve. Clin. Anat., 21(1):38-45, 2008.

Rouviere, H. \& Delmas, A. Anatomía humana: descriptiva, topográfica y funcional. 11th ed. Barcelona, Masson, 2005.

Santos, A. C. B.; Oliveira, F. M.; Oliveira, J. G.; Bolanho, E.; Roberti, T.; Mathias, U. U. M.; Costa, R. F. B. \& Fernandes Júnior, N. Aneurisma idiopático da artéria radial na região da tabaqueira anatômica: relato de caso. J. Vasc. Bras., 7(4):380-3, 2008.

Samarakoon, L. B.; Lakmal, K. C.; Thillainathan, S.; Bataduwaarachchi, V. R.; Anthony, D. J. \& Jayasekara, R. W. Anatomical relations of the superficial sensory branches of the radial nerve: a cadaveric study with clinical implications. Patient Saf. Surg., 5(1):28, 2011.
Stanziale, R.; Lodi, M.; D’Andrea, E. \& D'Andrea, T. Vascular access for hemodialysis: experience of a team of nephrologists. Hemodial. Int., 12(3):328-30, 2008.

Tao, W.; Dong-Yang, G.; Meng, W.; Ying, W. \& Fan, Z. Anatomical snuffbox versus forearm internal arteriovenous fistula for 214 hemodialysis patients with chronic renal failure: Which is the better method for permanent vascular access prior to kidney transplantation. J. Clin. Rehab. Tissue Eng. Res., 14(31):583740, 2010.

Testut, L. \& Latarjet, A. Compendio de Anatomía Descriptiva. Barcelona, Salvat Editores S. A., 1975.

Tubbs, R. S.; Salter, E. G. \& Oakes, W. J. The tabatière anatomique. Clin. Anat., 19(4):299-303, 2006.

Vialle, R.; Pietin-Vialle, C.; Cronier, P.; Brillu, C.; Villapadierna, F. \& Mercier P. Anatomic relations between the cephalic vein and the sensory branches of the radial nerve: How can nerve lesions during vein puncture be prevented? Anesth. Analg., 93(4):105861, 2001.

Walton, N. P. \& Choudhary, F. Idiopathic radial artery aneurysm in the anatomical snuff box. Acta Orthop. Belg., 68(3):292-4, 2002.

Wenger, D. R.; Boyer, D. W. \& Sandzén, S. C. Traumatic aneurysm of the radial artery in the anatomical snuff box--a report of two cases. Hand, 12(3):266-70, 1980.

Yoshii, S.; Ikeda, K. \& Murakami, H. Compression neuropathy of the superficial branch of the radial nerve. Case reports. Scan. J. Plast. Reconstr. Surg. Hand Surg., 34(1):93-5, 2000.

Yukios, U.; Matsuno, Y.; Imaizumi, M.; Mori, Y.; Iwata, H. \& Takiya, H. Bilateral radial artery aneurysms in the anatomical snuff box seen in marfan syndrome patient: case report and literature review. Ann. Vasc. Dis., 2(3):185-9, 2009.

\author{
Correspondence to: \\ Mariano del Sol Calderon \\ Facultad de Medicina \\ Universidad de La Frontera \\ Casilla $54 \mathrm{D}$ \\ Temuco \\ CHILE
}

Email: mariano.delsol@ufrontera.cl

Received: 15-01-2015

Accepted: 27-07-2015 